\title{
Self-selected exercise intensity for inactive hypertensive older women: a pilot study
}

\author{
Exercício em intensidade autosselecionada para mulheres idosas hipertensas inativas: \\ um estudo piloto
}

\section{AUTHOR'S \\ Júlio Sócrates ${ }^{1,2}$ (D) \\ Geovani Araújo Dantas Macêdo ${ }^{1}$ (D) \\ Ingrid Bezerra Barbosa Costa ${ }^{1}$ (D) \\ Rodrigo Alberto Vieira Browne ${ }^{1,2}$ (D) \\ Luiz Fernando Farias-Junior ${ }^{1,2}$ (D) \\ Yuri Alberto Freire ${ }^{1}$ (D) \\ Daniel Schwade ${ }^{1}$ (D) \\ Leandro Campos de Brito ${ }^{3}$ (D) \\ Hassan Mohamed Elsangedy ${ }^{1}$ (D) \\ Eduardo Caldas Costa ${ }^{1,2}$ (D) \\ 1 Federal University of Rio Grande do Norte, Department of Physical Education. Natal, Rio Grande do Norte, Brazil. \\ 2 Federal University of Rio Grande do Norte, Graduate Program in Health Sciences. \\ Natal, Rio Grande do Norte, Brazil. \\ 3 University of São Paulo, School of Physical \\ Education and Sport. São \\ Paulo, São Paulo, Brazil.}

\section{CORRESPONDING}

Eduardo Caldas Costa, PhD.

ecc@ufrnet.br

Department of Physical Education, Federal University of Rio Grande do Norte, University. Campus, BR 101, Lagoa Nova, Natal, Rio Grande do Norte, Brazil.

Zip Cod: 59078-970.

\section{DOI}

$10.12820 /$ rbafs. $24 \mathrm{e} 0084$

\section{(cc) BY-NC-SA}

This work is licensed under the Creative Commons Attribution-NonCommercial-ShareAlike 4.0 International License

\begin{abstract}
Self-selected exercise intensity (SSE) is a simple approach to encourage an active lifestyle. This study aimed to investigate whether a SSE session meet the recommended intensity for hypertension management (i.e. moderate-vigorous), and whether heart rate (HR), rating of perceived exertion (RPE) and affective responses are reproducible. Thirteen inactive hypertensive older women (age: $64.54 \pm$ 4.16 years; blood pressure: $122.51 / 62.15 \mathrm{mmHg}$ ) performed two 30 -minute SSE sessions outdoors. HR reserve (HRR), RPE and affective responses were assessed. Paired t-test, intraclass correlation coefficient (ICC) and typical error (TE) were used for the analyzes. Participants exercised at moderate-vigorous intensity ( $\geq 40 \%$ of HRR). No differences were found for HRR $(56.46 \pm 8.01 \%$ vs. $59.08 \pm 10.57 \%), \operatorname{RPE}(11.26 \pm 1.14$ vs. $10.98 \pm 1.52)$ and affective response $(3.47 \pm 1.13$ vs. $3.38 \pm$ $1.23)(\mathrm{p}>0.05)$. RPE showed excellent reliability ( $\mathrm{ICC}=0.82 ; 95 \% \mathrm{CI}: 0.42 ; 0.94 ; \mathrm{p}=0.003)$. There was a poor reliability for HRR (ICC $=0.40 ; 95 \% \mathrm{CI}$ : $-0.97 ; 0.82 ; \mathrm{p}=0.193$ ) and affective responses $(\mathrm{ICC}=0.19$; 95\% CI: $-2.10 ; 0.76 ; \mathrm{p}=0.369)$. TE between sessions for HRR, RPE, and affective response were $8.11 \mathrm{bpm}, 0.75$ and 1.11, respectively. In conclusion, inactive hypertensive older women seem to meet the recommended intensity for hypertension management when they exercise at a self-selected pace and report it as light-moderate and pleasant. Despite only RPE, but not HR and affective response, has shown good reproducibility, the results seem to support the use of SSE as a simple approach to encourage an active lifestyle in this population.
\end{abstract}

Keywords: Exercise; Hypertension; Blood pressure; Physical exertion; Affect.

\section{RESUMO}

O exercício em intensidade autosselecionada (EIA) é uma abordagem simples para encorajar um estilo de vida ativo. Este estudo investigou se o ELA atende a intensidade recomendada para tratamento de hipertensão (i.e. moderada-vigorosa), e se a frequência cardíaca (FC), percepção de esforço (PSE) e resposta afetiva são reprodutiveis. Treze mulheres idosas hipertensas inativas (idade: $64,54 \pm 4,16$ anos; pressão arterial: $122,51 / 62,15 \mathrm{mmHg}$ ) realizaram duas sessões de EIA de 30 minutos ao ar livre. FC de reserva (FCR), PSE e resposta afetiva foram avaliadas. Teste t pareado, coeficiente de correção intraclasse (CCI) e erro típico (ET) foram analisados. As participantes se exercitaram em intensidade moderada-vigorosa $(\geq 40 \%$ da FCR). Não houve diferença na FCR (56,46 $\pm 8,01 \%$ vs. 59,08 $\pm 10,57 \%)$, PSE $(11,26 \pm 1,14$ vs. 10,98 \pm 1,52) e resposta afetiva $(3,47 \pm 1,13$ vs. 3,38 $\pm 1,23 ; p>0,05)$. A PSE apresentou excelente confiabilidade $(C C I=0,82 ;$ IC95\%: 0,42; 0,94; $p=0,003)$. Houve baixa confiabilidade da FCR (CCI =0,40; IC95\%: $-0,97 ; 0,82 ; p=0,193)$ e resposta afetiva $(C C I=0,19 ; I C 95 \%:-2,10 ; 0,76 ; p=0,369)$. O ET foi de 8,11 bpm, 0,75 e 1,11 para FCR, PSE e resposta afetiva, respectivamente. Em conclusão, mulheres idosas bipertensas inativas parecem atender a intensidade recomendada para tratamento da bipertensão quando realizam EIA e relatam a atividade como leve-moderada e prazerosa. Embora apenas a PSE, e não a FCR e resposta afetiva, tenha mostrado boa reprodutibilidade, os resultados parecem suportar o ELA como uma abordagem simples para encorajar um estilo de vida ativo nessa população.

Palavras-chave: Exercício; Hipertensão; Pressão arterial; Esforço físico; Afeto.

\section{Introduction}

Hypertension accounts for 9.4 million deaths/year and affects $40 \%$ of adults ${ }^{1}$ and $\geq 60 \%$ of older adults ${ }^{2}$, mainly inactive individuals ${ }^{3}$. Efforts should be made to reduce blood pressure (BP) and its associated risk factors in older hypertensive adults to attenuate the risk of cardiovascular events and mortality ${ }^{1}$. Aerobic exercise is a cornerstone of non-pharmacological therapy for hypertension ${ }^{2}$. Hypertension guidelines recommend 30-60 minutes of moderate-intensity aerobic exercise most days of the week for hypertensive individuals ${ }^{4}$ in order to reduce resting ${ }^{5}$ and ambulatory ${ }^{6}$ BP. However, 
a home-focused epidemiological Brazilian study demonstrated that $71.4 \%$ of hypertensive older adults are physically inactive ${ }^{7}$.

Strategies to enhance participation and long-term adherence in regular physical exercise are needed in hypertensive population. Self-selected exercise intensity (SSE) is an alternative approach to formal exercise prescription to enhance participation due its psychological advantages, including higher perceived autonomy, self-efficacy, affective response, and lower perceived exertion ${ }^{8-10}$. Specifically regarding the affective response, hedonic theory supports the link between affective response and future exercise intentions ${ }^{9}$ and engagement ${ }^{11}$. For example, Williams et al. ${ }^{12}$ have found that a more positive affective response during a single moderate-intensity exercise session was associated with a higher physical activity level six and 12 months later. A systematic review conducted by Rhodes and Kates ${ }^{13}$ also supports the link between affective response during exercise and future physical activity behavior, which is postulated by hedonic theory. In addition, previous study have shown that exercise intensity recommended by physical activity guidelines is meet exercising at a self-selected pace ${ }^{4}$. However, this is not clear in hypertensive older women.

The antihypertensive effect of exercise is a result of physiological adjustments to repeated exercise sessions ${ }^{14}$. A single session of aerobic exercise at moderate-vigorous intensity elicit reduction of BP up to 24hour post-exercise without any clinical symptomatic hypotension, which is called post-exercise hypotension $(\mathrm{PEH})^{15}$. Recently, we have demonstrated that a SSEsession reduced 4.0 and $3.4 \mathrm{mmHg}$ in ambulatory systolic BP in the awake and 20 -hour periods, respective$1 y$, in inactive hypertensive older women ${ }^{16}$. In order to establish the clinical utility of the SSEfor hypertensive older women, it is important to determine its reproducibility, especially regarding the exercise intensity recommended to this population.

Therefore, this study aimed to: i) assess whether two sessions of SSEmeet the exercise intensity recommended by the physical activity guidelines in inactive hypertensive older women; and ii) to examine whether markers of exercise intensity (i.e. HR and RPE) and affective response are reproducible between two SSE sessions. We hypothesized that the participants would meet the exercise intensity recommended by the guidelines and that $\mathrm{HR}, \mathrm{RPE}$, and affective responses would be reproducible between two SSE sessions.

\section{Methods}

Participants performed the following procedures $\mathrm{du}-$ ring a 4-week period: i) initial health screening and body composition assessment; ii) office and ambulatory BP measurements; iii) assessment of physical activity level; iv) maximal graded exercise test; v) two SSE sessions. The study was conducted from August 2016 to May 2017 at the Department of Physical Education, Federal University of Rio Grande do Norte, Brazil. The Institutional Ethics Committee approved the study (protocol: 1526048). Participants were informed about all procedures of the study and gave written informed consent.

Participants were screened in the first visit using the Physical Activity Readiness Questionnaire, medical history. Afterward they underwent a clinical examination where body weight $(\mathrm{kg})$, height $(\mathrm{m})$, resting heart rate (HR), and resting $\mathrm{BP}(\mathrm{mmHg})$ were measured. Resting HR was measured after 10 minutes of rest in a supine position in a calm and controlled room (24-26 ${ }^{\circ} \mathrm{C}$ degrees) using a HR monitor (Polar Electro ${ }^{\circledR}, \mathrm{RS} 800 \mathrm{cx}, \mathrm{Oy}$, Kempele, Finland). Office BP was measured in a seated position using an oscillometric device (Omron ${ }^{\circledast}$ HEM-780-E, Japan) after the resting HR measurement. The participant's body composition was assessed by the dual-energy X-ray absorptiometry (GE Healthcare Lunar Prodigy Advance ${ }^{\oplus}$ USA). Lastly, an ambulatory BP monitoring device (CardioMAPA, Cardios ${ }^{\circledast}$, Brazil) was placed on the non-dominant arm of the participants in order to assess their 24-hour ambulatory BP. Participants returned to the laboratory on the following day to remove the device, and they were fitted with a waist pedometer $\left(\mathrm{Omron}^{\varpi}\right.$, HJ-321 Tri-Axis Alvita, USA) to assess the number of steps/day over a 1-week period.

On the third visit after 1-week, participants returned to the laboratory to remove the pedometer and perform a maximal graded exercise test on a treadmill in order to determine their maximal $\mathrm{HR}\left(\mathrm{HR}_{\max }\right)$. The first and second SSE sessions were performed in the next two weeks separated by 7-10 days. All procedures were performed in the morning (between 7:00-8:15 a.m.). Participants were instructed to abstain from moderate-vigorous physical activity and caffeinated products in the days of the maximal graded exercise test and the SSE sessions. Additionally, participants were instructed to abstain from alcohol, to maintain their eating habits and sleeping pattern during the 24-hour period before the SSE sessions. 
Thirteen participants were included in the final analysis. All participants were recruited from a previous study conducted by our research group, which was designed to investigate the acute effect of a single SSEsession on ambulatory BP in inactive hypertensive older women $(n=20)^{16}$. After the end of this previous study $^{16}$, all participants were invited to perform one additional SSEsession in order to assess the reproducibility of HR, RPE, and affective response. Seven of them declined to participate of this present study. Previously, these participants were recruited from the university cardiology outpatient service of the Federal University of Rio Grande do Norte, Brazil. Inclusion criteria were: i) age from 60 to 75 years; ii) previous diagnosis of hypertension according to the Brazilian Guidelines on Hypertension; iii) currently taking antihypertensive medication; iv) no participation in exercise training programs in the last six months; v) being inactive; i.e. less than 7,500 steps $/$ day $^{17}$; vi) no known cardiovascular, metabolic, musculoskeletal or respiratory disease; vii) no musculoskeletal condition that limits the ability to exercise at moderate-vigorous intensity (i.e. knee arthritis or pain). Exclusion criteria were: i) pain/injury that limits the ability to exercise during the study; ii) changes in antihypertensive medication during the study; iii) electrocardiographic (ECG) alterations during the maximal graded exercise test suggested of heart disease.

Participants performed a maximal graded exercise test on a motorized treadmill to determine their $\mathrm{HR}_{\max }$ and to exclude ECG alterations suggested of heart disease. A cardiologist conducted the test and the participants were continuously monitored with a 12 lead ECG. After a 2-minutes warm-up, an incremental ramp protocol was performed by the participants starting at a speed of $2.50 \mathrm{~km} / \mathrm{h}$ without gradient and increasing $0.3 \mathrm{~km} / \mathrm{h}$ and $1 \%$ grade every minute until volitional exhaustion. The participant's physical effort was assessed every minute using Borg's (6-20) RPE Scale $^{18}$ and the BP was measured every minute and immediately following volitional exhaustion. Graded exercise test was considered maximal when the participant reached a RPE higher than 17 and a HR within $\pm 10 \mathrm{bpm}$ of age-predicted maximal HR (220-age). All participants exercised while taking their antihypertensive medications. Only the RPE was used as a criterion of volitional exhaustion for the participants taking beta-blocker. All participants were encouraged to reach their maximal effort during the test.
The pedometer (Omron ${ }^{\oplus}, \mathrm{HJ}-321$ Tri-Axis Alvita, USA) was individually adjusted for the participants using their stride length, weight and height according to the manufacturer's instructions. The number of steps per day $\leq 7,500$ was used as a criterion to classify the participants as "inactive' ${ }^{\text {'17 }}$. Moreover, the number of steps per day performed at a moderate cadence (i.e. 60 steps/minute $)^{17}$ at least 10 minutes continuously was recorded. This variable was recorded to certify that the participants walked $\leq 30$ minutes per day at a moderate cadence (i.e. 1,800 steps) continuously or in bouts of at least 10 minutes.

Office BP (Omron ${ }^{\oplus}$ HEM-780-E, Japan) was measured in triplicate after 10 minutes of resting with 1-minute interval between each measure and the average value of the last two measures was recorded. An oscillometric device (CardioMAPA, Cardios ${ }^{\circledR}$, Brazil) was placed on the participants' non-dominant arm to assess their ambulatory BP during 24-hours, according to the VI Brazilian guidelines for ambulatory BP monitoring ${ }^{19}$. The measures $\mathrm{BP}$ was programmed for every 15 -minutes during awake and every 30 -minutes during asleep.

SSE sessions were performed in the morning (between 7:00-8:15 a.m.) on a standard outdoor 400-m track. The temperature $\left(27.0-27.5^{\circ} \mathrm{C}\right)$ and humidity (70-85\%) were similar between the SSE sessions. Each participant was fitted with a HR monitor (Polar Electro ${ }^{\circledR}, \mathrm{Oy}$, Kempele, Finland) and they were instructed to regulate their own pace according to the following instruction: 'We would like that you exercise for 30-minutes at a pace of your own choosing. You can freely change the pace at any time during the exercise'. After a stretching routine, the participants warmed up for 5-minutes in order to adjust their pace. SSE sessions were performed individually. Ad libitum water intake was allowed. HR was continuously recorded throughout the SSE sessions and the participants reported their whole-body RPE using Borg's (6-20) RPE scale ${ }^{18}$ and basic affect using the Feeling Scale $(-5 /+5)^{20}$ every 10-minutes.

Participants were instructed regarding the RPE scale $^{18}$ and the Feeling Scale ${ }^{20}$ use with verbal and memory anchoring at the screening visit and immediately before each SSEsession. Perceived exertion was defined as the subjective intensity of effort, strain, and/or fatigue that the participants can feel during exercise $^{18}$. The Feeling Scale ${ }^{20}$ is an 11-point bipolar scale ranging from +5 to -5 (i.e. $+5=$ very good; +3 
= good; +1 = fairly good; 0 = neutral; -1 = fairly bad; $-3=$ bad; $-5=$ very bad) commonly used to measure affect (feelings of pleasure/displeasure) during exercise, and it is recommended by the American College of Sports Medicine ${ }^{21}$. The participants received standard instructions regarding the FS according to Hardy and Rejeski ${ }^{20}$. The RPE scale and FS were presented in a randomized order to the participants.

Data were tested for normality using the Shapiro-Wilk's test. Descriptive variables were expressed as mean \pm standard deviation (SD). As all data had normal distribution, heteroscedasticity was assessed using Pearson's product-moment correlation coefficient between the mean and absolute difference of the first and second SSE sessions. Heteroscedasticity is considered present if the Pearson's product-moment correlation coefficient is significant. Paired sample t-test was used to verify systematic error regarding to differences in mean values. Intraclass correlation coefficient (ICC) was used to verify reliability, and was considered as poor ICC $<0.40$, as fair to good ICC between 0.40 and 0.75 , and as excellent ICC $\geq 0.75$. As no variable presented heteroscedasticity, agreement was assessed using typical error (TE). A two-way (SSE sessions vs. time) repeated measures analysis of variance was used to compare HR, RPE and affective response between sessions. In the case of a sphericity assumption violation, the degrees of freedom were adjusted and reported using the Greenhouse-Geisser epsilon correction. Partial eta squared (partial $\eta^{2}$ ) was used to determine the effect size of the variance. Bonferroni's post hoc tests were used to adjust for multiple comparisons. A p $<0.05$ was considered statistically significant. All data were analyzed using SPSS ${ }^{\circledR}$ version 25.0 for Windows (IBM, Inc., Chicago, IL, USA).

\section{Results}

Most participants were taking one antihypertensive medication $(61 \% ; n=8)$ and $(39 \% ; n=5)$ two or more medications. All participants presented controlled resting $(<140 / 90 \mathrm{mmHg})$ and 24-hour ambulatory (< 130/80 mmHg) BP levels (Table 1). All participants completed the two SSE sessions.

Figure $1 \mathrm{~A}$ presents the individual average HR during the SSE sessions. Regarding HR, 77\% $(\mathrm{n}=10)$ of the participants exercised at a moderate (i.e. $40-59 \%$ of $\mathrm{HRR})$ and $23 \%(\mathrm{n}=3)$ at a vigorous intensity (i.e. $\geq$ $60 \%$ of HRR) during the first session, while on the second session, $46 \%(n=6)$ exercised at moderate and $46 \%$
Table 1 - Characteristics of the participants $(n=13)$ from Natal, Rio Grande do Norte, 2016-2017

\begin{tabular}{lc}
\hline Variables & Mean \pm SD or $\mathrm{n}(\%)$ \\
\hline Age (years) & $64.54 \pm 4.16$ \\
Diagnosis of hypertension (years) & $12.27 \pm 10.69$ \\
Body mass index $\left(\mathrm{kg} / \mathrm{m}^{2}\right)$ & $29.33 \pm 4.86$ \\
Body fat $(\%)$ & $43.39 \pm 5.90$ \\
Resting SBP $(\mathrm{mmHg})$ & $122.51 \pm 12.45$ \\
Resting DBP $(\mathrm{mmHg})$ & $62.15 \pm 7.97$ \\
24-h ambulatory SBP $(\mathrm{mmHg})$ & $119.20 \pm 9.77$ \\
24-h ambulatory DBP $(\mathrm{mmHg})$ & $64.72 \pm 8.10$ \\
Resting heart rate (bpm) & $61.15 \pm 8.33$ \\
Maximal heart rate at GXT (bpm) & $154.54 \pm 16.79$ \\
Total steps (amount per day) & $5.409 \pm 2.043$ \\
Continuous steps ( $\geq 10$ min, $\geq 60$ steps $/$ min) & $778.38 \pm 757.02$ \\
Antihypertensive medications & \\
Calcium channel blocker & $3(23 \%)$ \\
Diuretics & $3(23 \%)$ \\
Angiotensin receptor antagonists & $8(61 \%)$ \\
Beta-blocker & $2(15 \%)$ \\
Angiotensin converting enzyme inhibitor & $1(8 \%)$ \\
\hline
\end{tabular}

$\mathrm{SBP}=$ systolic blood pressure; DBP = diastolic blood pressure; GXT $=$ graded exercise test.

*Amount of continuous steps at a pace higher than 60 steps per minute performed at least 10 minutes continuously per day.

$(n=6)$ at vigorous intensity. There was no difference in the exercise intensity over 10, 20 and 30 minutes between first and second SSE sessions, respectively, [52.62 \pm 7.71 vs $54.00 \pm 10.14 ; 56.15 \pm 6.77$ vs $59.46 \pm 10.75$; $58.69 \pm 7.57$ vs $63.85 \pm 12.12 ; \mathrm{F}(1.38,16.57)=3.75 ; \mathrm{p}$ $=0.059 ;$ partial $\left.\eta^{2}=0.238\right]-$ Figure 1B.

Figure $2 \mathrm{~A}$ presents the individual average $\mathrm{RPE}$ during the SSE sessions. Regarding RPE, 62\% ( $n=8)$ reported light (i.e. $<12$, Borg's RPE) and 38\% ( $=5)$ moderate (i.e. 12-13, Borg's RPE) perceived exertion during both SSE sessions. There was no difference in the RPE reported over 10, 20 and 30 minutes between first and second SSE sessions, respectively [11.08 \pm 0.86 vs $10.46 \pm 1.45 ; 11.23 \pm 1.30$ vs $11.00 \pm 1.78$; $11.46 \pm 1.51$ vs $11.46 \pm 1.56 ; \mathrm{F}(2.00,24.00)=1.32 ; \mathrm{p}$ $=0.285 ;$ partial $\left.\eta^{2}=0.099\right]-$ Figure $2 \mathrm{~B}$.

Figure $3 \mathrm{~A}$ presents the individual average affect during the SSE sessions. All participants reported positive affect (i.e. $\geq 1$ on the Feeling Scale) during both SSE sessions. Specifically, 23\% $(n=3)$ reported fairly good (i.e. between 1 and $<3$ on the Feeling Scale) and $77 \%(n=10)$ good or higher affect (i.e. $\geq 3$ on the Feeling Scale) during both SSE sessions. There was no difference in the affect over 10, 20 and 30 minutes between first and second SSE sessions, respectively [3.23 


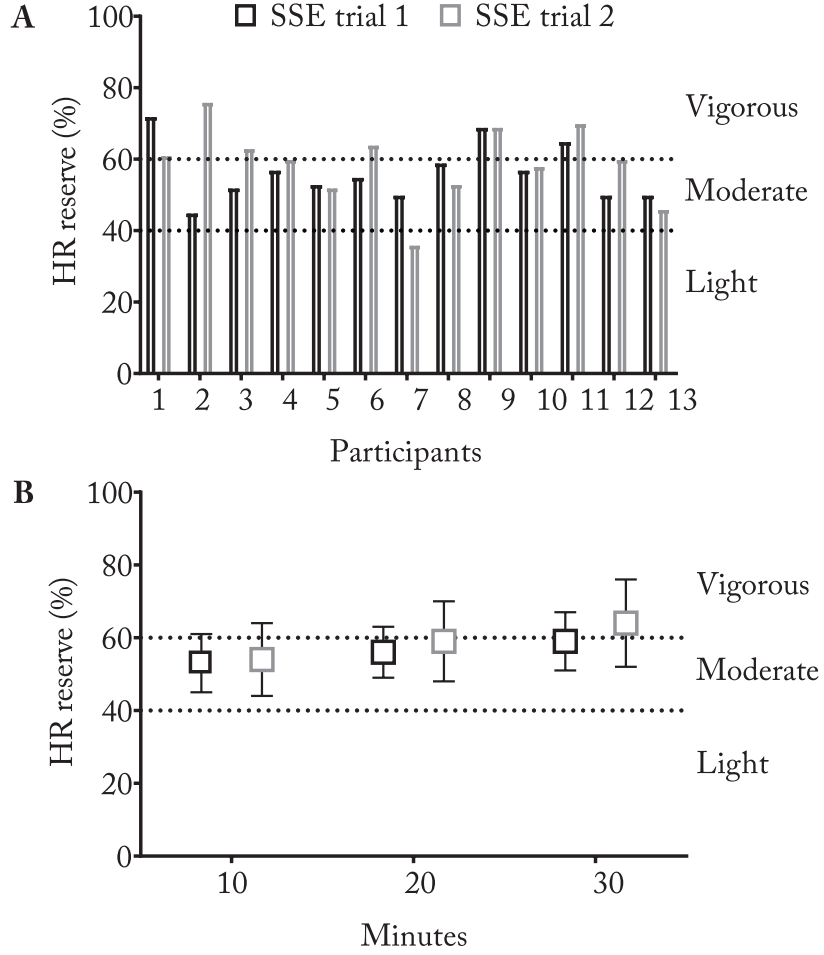

Figure 1 - Individual average heart rate (Panel A) and heart rate (Panel B) responses of the inactive hypertensive older women during the self-selected exercise intensity trials. Natal, Rio Grande do Norte, 2016-2017. HR = heart rate; SSE = self-selected exercise.

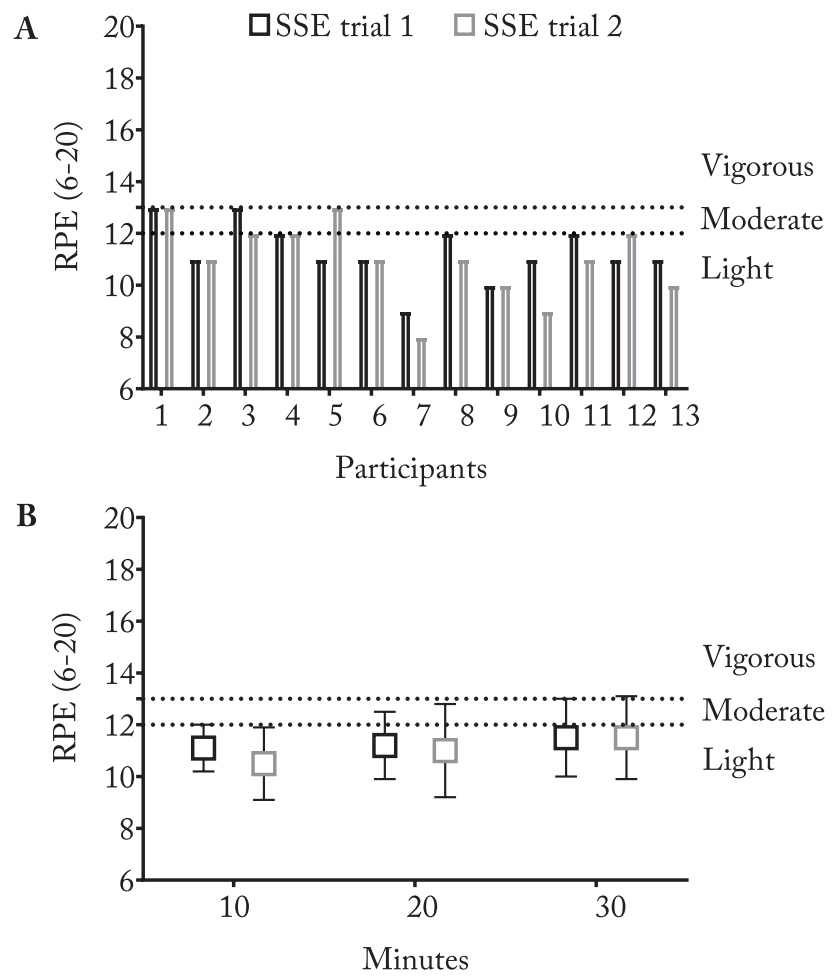

Figure 2 - Individual average perceived exertion (Panel A) and perceived exertion (Panel B) reported by the inactive hypertensive older women during the self-selected exercise intensity trials. Natal, Rio Grande do Norte, 2016-2017. RPE = rating of perceived exertion; $\mathrm{SSE}=$ self-selected exercise. \pm 1.17 vs $3.46 \pm 1.20 ; 3.69 \pm 1.44$ vs $3.31 \pm 1.44 ; 3.46 \pm$ 1.33 vs. $3.38 \pm 1.61 ; \mathrm{F}(2.00,24.00)=0.96 ; \mathrm{p}=0.398$; partial $\left.\eta^{2}=0.074\right]-$ Figure $2 B$.

$\square$ SSE trial $1 \quad \square$ SSE trial 2
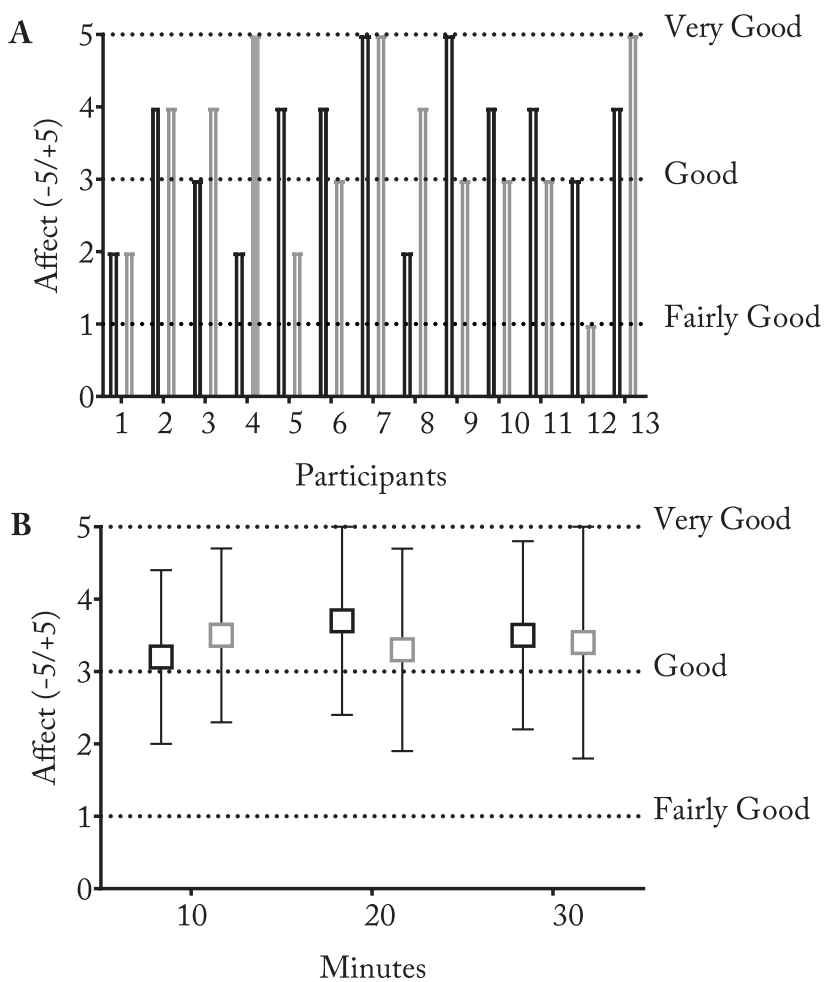

Figure 3 - Individual average affect (Panel A) and affect (Panel B) reported by the inactive hypertensive older women during the self-selected exercise intensity trials. Natal, Rio Grande do Norte, 2016-2017. SSE = self-selected exercise.

Table 2 presents the reproducibility results of $\mathrm{HR}$, $\mathrm{RPE}$ and affective responses. Average HR, RPE, and affective responses were not different between the SSE sessions ( $p>0.05)$. RPE presented excellent reliability $(\mathrm{ICC}=0.82 ; \mathrm{p}=0.003)$. However, there were no reliability for $\mathrm{HR}(\mathrm{ICC}=0.40, \mathrm{p}=0.193)$ and affective responses $(\mathrm{ICC}=0.19 ; \mathrm{p}=0.369)$. The typical error between the SSE sessions for HR, RPE and affect responses were $8.11 \mathrm{bpm}, 0.75$ and 1.11 , respectively.

\section{Discussion}

The main findings of this study were: i) inactive hypertensive older women self-selected a moderate-vigorous intensity during the SSE sessions, meeting the recommendations of the physical activity guidelines; and ii) only the RPE presented reproducibility between SSE sessions. SSE sessions were reported as light-moderate (i.e., RPE $\leq 13$, "somewhat hard"). Despite the absence of good reproducibility for HR and affective respon- 
Table 2 - Reproducibility parameters of heart rate, rating of perceived exertion and affective response during the self-selected exercise intensity trails in inactive hypertensive older women from Natal, Rio Grande do Norte, 2016-2017

\begin{tabular}{lcccccc}
\hline & SSE trial 1 & SSE trial 2 & $p$ & ICC $(95 \%$ CI $)$ & p & TE \\
\hline HRR (\%) & $56.46 \pm 8.01$ & $59.08 \pm 10.57$ & 0.427 & $0.40(-0.97 ; 0.82)$ & 0.193 & 8.11 \\
RPE (6-20) & $11.26 \pm 1.14$ & $10.98 \pm 1.52$ & 0.350 & $0.82(0.42 ; 0.94)$ & 0.003 & 0.75 \\
Affect $(-5 /+5)$ & $3.47 \pm 1.13$ & $3.38 \pm 1.23$ & 0.851 & $0.19(-2.10 ; 0.76)$ & 0.369 & 1.11 \\
\hline
\end{tabular}

$\mathrm{HRR}=$ heart rate reserve; $\mathrm{RPE}=$ rating of perceived exertion; $\mathrm{ICC}=$ intraclass correlation coefficient; $\mathrm{CI}=$ confidence interval; $\mathrm{TE}=$ typical error.

se between the SSE sessions, all participants exercised above $40 \%$ of HRR (i.e. moderate-vigorous) and reported positive affective (i.e., $\geq 1$, "good to fairly good").

All participants exercised within the moderate-vigorous intensity (i.e. $\geq 40 \%$ of HRR) as previously observed in middle-aged and older inactive adults and obese individuals during SSE sessions ${ }^{22}$. This exercise intensity is recommended by hypertension guidelines to improve health-related physical fitness, reduce BP and reduce additional cardiovascular risk factors ${ }^{4}$. Our finding regarding the RPE and affect seems to support the SSEas a simple exercise approach for inactive hypertensive older women whose present low adherence to physical exercise programs. Thus, our results could have relevance for a public health perspective, encouraging inactive hypertensive older women to meet the physical activity levels recommended in the current hypertension guidelines ${ }^{4}$. However, it is important to highlight that adherence to exercise programs is complex and multifactorial. Therefore, our results showed that SSEcould contribute to improve exercise adherence considering specifically the RPE and affective response.

HR responses were not reproducible. Specifically, we did not observe significantly reliability of HR between the SSE sessions (Table 2), suggesting an intra-individual variability of the HR responses between the exercise sessions. This lack of reliability may have occurred because physical exercise is a psychobiological phenomenon, and the intra-individual variability of the physiological responses and adjustments could be explained by some psychological interpretations (e.g. familiarization and previous experience with exercise, self-efficacy, and body consciousness) in each SSEsession among the participants. Regarding the inter-individual variability of the HR responses during SSE sessions, previous studies have confirmed this phenomenon ${ }^{22}$. However, we highlight that despite lack reliability of HR responses, all participants exercised within moderate-vigorous exercise intensity $(56.5 \%$ and $59.1 \%$ of HRR) during both SSE sessions. Ad- ditionally, SSEseems to be a simple and safe exercise approach for this population because typically the individuals self-select an exercise intensity below their ventilatory or lactate thresholds ${ }^{22}$, which is effective to improve health and fitness and mitigating the risk of musculoskeletal injury and adverse cardiovascular events, especially when it is performed without professional supervision. Therefore, we suggest that SSEshould be encouraged in a public health perspective, which could reduce the economic burden of physical inactivity on the health-care system ${ }^{23}$, seeing that $\mathrm{ex}^{-}$ penditures for controlling hypertension in older adults is high and inversely associated with physical activity level and engagement in walking ${ }^{7}$.

RPE showed good reproducibility, and it has been described as the single best indicator of the degree of physical strain ${ }^{18}$. This response has been associated with a reproducible pacing strategy in different contexts $^{24}$. Recently, an integrative model ${ }^{22}$ has recognized the conscious sensation of fatigue (i.e. RPE responses) as a sensory representation resulting from the competition between the physiological and psychological drives. The relative weighting of these competing drives that are underpinned by the principle of homeostasis determine the decision-making process associated with pacing strategy selection ${ }^{21}$. Furthermore, when an individual is allowed to select the exercise intensity, there is a tendency to seek a pace close to their ventilatory threshold ${ }^{8-10}$ and this intensity has been associated with a constant $\mathrm{RPE}^{25}$. It seems that the autonomy of self-selecting an intensity to exercise may establish a direct relationship of regulating these physiological and psychological parameters, allowing individuals to keep a stable perceived state in face of psychophysiological variations. Indeed, our results showed that RPE is a reliable response between the SSE sessions.

Further, participants reported a RPE as light (i.e. RPE 11) during the SSE sessions. SSEattenuates the perceived exertion by allowing the individual to cognitively self-regulate their experience during exer- 
cise, which may increase their perceived autonomy ${ }^{10}$. The different stimuli from an outdoor environment seems to reduce the internal attention focus (e.g. increased HR and breath) and increase the more externally focused attentional focus ${ }^{8}$. Recently, Krinski et al. ${ }^{9}$ showed that women with obesity presented lower RPE, higher dissociative attention and higher affective responses during outdoor SSEwhen compared to an indoor environment with a similar oxygen uptake and HR responses. Thus, it seems that there are psychological differences during outdoor SSEsession, given that individuals report a lower RPE than expected for moderate-vigorous exercise intensity.

Regarding the feelings of pleasure/displeasure during the SSE sessions, we observed that although the participants reported both exercise sessions as pleasant, the magnitude of affective responses was not reproducible as demonstrated by a lack of reliability. Considering the pleasure and displeasure domains of the basic affect that can be assessed by the Feeling Scale, the participants were clearly able to distinguish these two domains, consistently reporting the SSE sessions as pleasant. However, it seems that the interpretation and assessment of the magnitude of the basic affect within the pleasure domain becomes a more complex task. Therefore, this conflict may generate affective responses that are not similar intra-individuals between SSE sessions, which may partially explain the lack of reliability for affective responses. Nonetheless, we believe that the affective responses may become more precise over time, with additional exercise training sessions and more familiarity with the Feeling Scale.

Both SSE sessions were pleasant. This can be partially explained by the magnitude of the metabolic stress imposed to the organism because, typically, the individuals self-select an exercise intensity below the anaerobic threshold ${ }^{26}$. Previously, it was demonstrated that the SSEis defined by the maintenance of a stable and positive affective state, which is close but below the anaerobic threshold ${ }^{8}$. The feelings of pleasure and well-being seem to have a decisive role for engagement in the exercise programs when compared to the levels of information and knowledge about the benefits of physical activity ${ }^{27}$. This is supported by the hedonic theory of motivation ${ }^{11}$. Therefore, the recommendation of the SSEoutdoors seems to be an interesting strategy for inactive hypertensive older women because it is an exercise approach pleasant, beyond to meeting the recommended physical activity ${ }^{4}$. In addition, it should be noted that the participants of the present study showed high $\%$ of body fat (i.e. $43.39 \pm 5.90$ ), which characterizes them as obese. Obese individuals have a lower affective response than normal weight and overweight individuals from light to vigorous intensities ${ }^{28}$. We have observed that even exercising at a moderate to vigorous intensity at a self-selected pace, the participants reported positive affective response, which could contribute to a better exercise engagement mainly in the first exercise sessions.

It should be noted that low tolerance to effort is one of the main causes for the lack of engagement in physical exercise programs by hypertensive population ${ }^{29}$ and unpleasant experiences during exercise is commonly reported as a barrier by older adults ${ }^{30}$. Therefore, our results seem to support the use of the SSEas a simple and safe approach to encourage an active lifestyle in inactive hypertensive older women. Future studies should investigate whether aerobic SSEinterventions can elicit chronic BP-lowering effect, reduction in cardiovascular disease risk and improvements in cardiorespiratory fitness in hypertensive older adults.

Some limitations should be mentioned. First, only HR was monitored as an objective marker to characterize the intensity of the SSE sessions. Thus, it is not possible to characterize the sessions according to oxygen uptake and different metabolic domains (below, at or above the ventilatory threshold). Second, only two SSE sessions were performed to assess the reproducibility of the investigated variables. Lastly, this study involved a small sample of inactive hypertensive older women without other cardiovascular disease. Therefore, these findings may not be generalizable to other hypertensive populations. In conclusion, this pilot study suggests that inactive hypertensive older women without other cardiovascular disease seem to choose a moderate-vigorous intensity (i.e. $\geq 40 \%$ of HRR) when they exercise at a self-selected pace. Further, it also suggests that their perceived exertion and affective response is light-moderate and pleasant, respectively. Despite the lack of reproducibility of the HR and affective response, all participants exercised within the HRR zone recommended by the physical activity guidelines for hypertension management and reported feelings of pleasure consistently. Future studies including a large and representative sample of hypertensive older women should be conducted in order to confirm (or not) our preliminary results. 


\section{Conflict of interest}

The authors declare no conflict of interest.

\section{Authors' contributions}

Sócrates J, Macêdo GAD and Costa IBB contributed to conception of the study, acquisition, analysis, and interpretation, and drafted the manuscript. Browne RAV, Farias-Junior LF, Freire YA and Schwade D contributed to acquisition, analysis, and interpretation, and critically revised the manuscript. Brito LC and Elsangedy HM contribute to interpretation and critically revised the manuscript. Costa EC contributed to conception of the study, analysis, and interpretation, and critically revised the manuscript.

\section{Acknowledgements}

The authors are grateful for the students' scholarships at undergraduate (Conselho Nacional de Desenvolvimento Científico e Tecnológico [CNPq]), master's (Coordenação de Aperfeiçoamento de Pessoal de Nível Superior [CAPES]), and PhD (CAPES) levels. The funders had no role in study design, data collection and analysis, decision to publish, or preparation of this manuscript.

\section{References}

1. World Health Organization. A global brief on Hypertension - World Health Day 2013. World Heal Organ. 2013;39.

2. Whelton PK, Carey RM, Aronow WS, Casey DE, Collins $\mathrm{KJ}$, Dennison $\mathrm{HC}$, et al. Guideline for the Prevention, Detection, Evaluation, and Management of High Blood Pressure in Adults. Hypertension. 2018;71:e13-e115.

3. Rissardi GGL, Cipullo JP, Moreira GC, Ciorlia LAS, Cesarino CB, Zanesco A, et al. Prevalence of physical inactivity and ist effects on blood pressure and metabolic parameters in a Brazilian urban population. Int J Cardiovasc Sci. 2018;31(6):594-602.

4. Pescatello LS, Macdonald HV, Ash GI, Lamberti LM, Farquhar WB, Arena R, et al. Assessing the existing professional exercise recommendations for hypertension: A review and recommendations for future research priorities. Mayo Clin Proc. 2015;90(6):801-12.

5. Cornelissen VA, Smart NA. Exercise training for blood pressure: a systematic review and meta-analysis. J Am Heart Assoc. 2013;2(1):e004473.

6. Sosner P, Guiraud T, Gremeaux V, Arvisais D, Herpin D, Bosquet L. The ambulatory hypotensive effect of aerobic training: a reappraisal through a meta-analysis of selected moderators. Scand J Med Sci Sports. 2017;27(3):327-41.

7. Bueno DR, Marucci MFN, Gobbo LA, Roediger MA, Duarte YAO, Lebrão ML. Expenditures of medicine use in hypertensive / diabetic elderly and physical activity and engagement in walking : cross secctional analysis of SABE Survey. BMC Geriatr. 2017;17:70.

8. Lind E, Matre RRJ, Ekkekakis P. What intensity of physical activity do previously sedentary middle-aged women select? Evidence of a coherent pattern from physiological, perceptual, and affective markers. Prev Med. 2005;40(4):407-19.

9. Krinski K, Machado DGS, Lirani LS, Silva SG, Costa EC, Hardcastle SJ, et al.Let's Walk Outdoors! Self-Paced Walking Outdoors Improves Future Intention to Exercise in Women With Obesity.J Sport Exerc Psychol. 2017;39(2):145-57.
10. Ekkekakis P, Parfitt G, Petruzzello SJ. The Pleasure and Displeasure People Feel When they Exercise at Different Intensities Decennial Update and Progress towards a Tripartite Rationale for exercise intensity prescription. Sport Med. 2011;41(8):641-71.

11. Kahneman D, Diener D, Schwarz N. Objective happiness. The foundation of hedonic psychology. 1999;3-25.

12. Williams DM, Dunsiger S, Ciccolo JT, Lewis BA, Albrecht AE, Marcus BH. Acute Affective Response to a Moderateintensity Exercise Stimulus Predicts Physical Activity Participation 6 and 12 Months Later. Psychol Sport Exerc. 2008;9(3):231-45.

13. Ryan E. Rhodes AK. Can the Affective Response to Exercise Predict Future Motives and Physical Activity Behavior? A Systematic Review of Published Evidence. Soc Behav Med. 2015;49(5):715-31.

14. Ghadieh AS, Saab B. Evidence for exercise training in the management of hypertension in adults. Can Fam Physician. 2015;61(3):233-9.

15. Brito LC, Fecchio RY, Peçanha T, Lima AA, Halliwill JR, Forjaz CLM. Postexercise hypotension as a clinical tool: a "single brick" in the wall. J Am Soc Hypertens. 2018;12(12):e59-64.

16. Costa IBB, Schwade D, Macêdo GAD, Browne RAV, Junior LFF, Freire YA, et al. Acute antihypertensive effect of self selected exercise intensity in older women with hypertension: a crossover trial. Clin Interv Aging. 2019;14;1-12

17. Tudor-Locke C, Hatano Y, Pangrazi RP, Kang M. Revisiting "how many steps are enough?". Med Sci Sports Exerc. 2008;40(Suppl 7):S537-43.

18. Borg G. The Borg RPE Scale. In: Borg's perceived exertion and pain scales. Champaign, IL: Human Kinetics; 1998;29-38.

19. Sociedade Brasileira de Cardiologia. 6a Diretrizes de Monitoramento Ambulatotial da Pressão Aterial e 4a Diretrizes de Monitoramento Residencial da Pressão Arterial. Arq Bras Cardiol. 2018;110(Suppl 5).

20. Hardy CJ, Rejeski WJ. Not What, but How One Feels: The Measurement of Affect during Exercise. J Sport Exerc Psychol. 1989;11(3):304-17.

21. Garber CE, Blissmer B, Deschenes MR, Franklin BA, Lamonte MJ, Lee IM, et al. Quantity and quality of exercise for developing and maintaining cardiorespiratory, musculoskeletal, and neuromotor fitness in apparently healthy adults: Guidance for prescribing exercise. Med Sci Sports Exerc. 2011;43(7):1334-59.

22. Ekkekakis P. Let them roam free? Physiological and psychological evidence for the potential of selfselected exercise intensity in public health. Sport Med. 2009;39(10):857-88.

23. Ding D, Lawson KD, Kolbe-Alexander TL, Finkelstein EA, Katzmarzyk PT, van Mechelen W, et al. The economic burden of physical inactivity: a global analysis of major noncommunicable diseases. Lancet. 2016;388(10051):1311-24.

24. Schallig W, Veneman T, Noordhof DA, Rodríguez-Marroyo JA, Porcari JP, de Koning JJ, et al. The Role of the Rating-ofPerceived-Exertion Template in Pacing. Int J Sports Physiol Perform. 2018;13(3):367-73.

25. Elsangedy HM, Krinski K, Costa EC, Haile L, Fonteles AI, Silva TL, et al. The rating of perceived exertion is not different at the ventilatory threshold in sedentary women with different body mass indices. J Exerc Sci Fit. 2013;11(2):102-6.

26. Ekkekakis P.The Dual-Mode Theory of affective responses to exercise in metatheoretical context: II. Bodiless heads, ethereal cognitive schemata, and other improbable dualistic creatures, exercising. Int Rev Sport Exerc Psychol. 2009;2(2):139-60. 
27. Dishman RK, Sallis JF, Orenstein DR. The determinants of physical activity and exercise. Public Health Rep. 1984;100(2):158-71.

28. Ekkekakis P, Lind E, Vazou S. Affective Responses to Increasing Levels of Exercise Intensity in Normal-weight, Overweight, and Obese Middle-aged Women. Obesity. 2009;18(1):79-85.

29. Martins LCG, Lopes MVO, Guedes NG, Mendes Nunes MI, Maciel Diniz C, Nunes MM, Diniz CM, Carvalho PMO. Sedentary lifestyle in individuals with hypertension. Rev Bras Enferm. 2015;68(6):697-704.
30. Groot GCL, Fagerström L. Older adults' motivating factors and barriers to exercise to prevent falls. Scand J Occup Ther. 2011;18(2):153-60.

\section{Quote this article as:}

Sócrates J, Macêdo GAD, Costa IBB, Browne RAV, Farias-Junior LF, Freire YA, Schwade D, Brito LC, Elsangedy HM, Costa EC. Self-selected exercise intensity for inactive hypertensive older women: a pilot study. Rev Bras Ativ Fis Saúde. 2019;24:e0084. DOI: 10.12820/rbafs.24e0084 